\title{
Applications of shape memory alloys in civil engineering structures - Overview, limits and new ideas
}

\author{
L. Janke ${ }^{1,2}$, C. Czaderski ${ }^{1}$, M. Motavalli ${ }^{1}$ and J. Ruth ${ }^{2}$ \\ (1) Empa, Swiss Federal Laboratories for Materials Testing and Research, Structural Engineering Research Laboratory, \\ Überlandstrasse 129, CH-8600 Dübendorf, Switzerland \\ (2) Bauhaus-University Weimar, Faculty of Civil Engineering, Germany
}

Received: 29 November 2004; accepted: 18 January 2005

\begin{abstract}
Shape memory alloys (SMAs) are metallic materials with great potential to enhance civil engineering structures. They are often referred to as smart materials. A basic description of their highly non-linear material behaviour in terms of shape memory effect, superelasticity, martensite damping and variable stiffness is given in this article. It is followed by a brief introduction to Ni-Ti and Fe-Mn-Si SMAs. Preexisting and new applications in the fields of damping, active vibration control and prestressing or posttensioning of structures with fibres and tendons are being reviewed with regard to civil engineering. Furthermore, the relatively high costs and the problem of retaining posttensioning forces when using some types of SMAs are named. In this regard is Fe-Mn-Si-Cr discussed as potential low cost SMA. A simple model for calculating the activation times of resistive heated SMA actuators or springs is presented. The results and measured data lead to further constrictions. Finally, new ideas for using SMAs in civil engineering structures are proposed in this article such as an improved concept for the active confinement of concrete members. This article is to introduce civil engineers to the world of shape memory alloys and invite them to contribute to their wider use in civil engineering structures.

1359-5997 (C) 2005 RILEM. All rights reserved.

\section{RÉSUMÉ}

Les alliages à mémoire de forme (AMF), souvent qualifiés de "matériaux intelligents », présentent un grand potentiel pour l'amélioration des ouvrages de génie civil. Une description de leurs comportements non linéaires, que sont la ménoire de forme, la superélasticité, la capacité d'amortissement de la martensite et la rigidité variable, est donnée. Elle est suivie d'une introduction sur les AMF Ni-Ti et Fe-Mn-Si. Des applications telles que l'amortissement et le contrôle actif des vibrations ou la pré- ou postcontrainte cut moyen de fibres et de câbles sont décrites. Les problèmes du coût des AFM et du maintien de la postcontrainte rencontré avec certains AFM sont aussi abordés. L'alliage Fe-Mn-Si-Cr est discuté comme AMF potentiellement bon marché. Un modèle du temps d'activation des actuateurs ou des ressorts en AMF chauffés par résistance est présenté. Cette modélisation et les résultats de mesure montrent que l'utilisation de ces AMF reste soumise à certaines restrictions. Finalement, de nouvelles applications des AMF en génie civil, telles qu'ume méthode de confinement actif des éléments en béton, sont présentées. Cet article se propose d'introduire les ingénieurs en génie civil dans l'univers des AMF pour les inciter à contribuer à leur plus large utilisation.
\end{abstract}

\section{INTRODUCTION}

In order to design and build a civil structure today, it takes more than just meeting the needs of functionality and load carrying capacity under static loads. There is an increasing demand for slender, wide spanned structures with high adaptability to changes in use: Yet another aim is the reduction of structural mass for economic reasons. All these factors make the work of civil engineers more challenging.

However, an equally important task for civil engineers is the sustainment of existing structures. Very often this is rather difficult, as insufficiencies in the original design or new loads oppose this aim.

Therefore the concept of smart structures and adaptive systems is relevant globally. For that reason, civil engineers are seeking new materials and technologies and are going beyond their habitual way of thinking. One of these materials are shape memory alloys, which are often regarded to be 'smart materials.'

Although SMAs have been known for decades, they have not been used much in the building industry until rather recently. The complete understanding and control of their 
extraordinary properties and of the associated metallographic processes are still being developed. Nevertheless, the current state of the art provides more than an adequate basis for giving an overview of the possible applications of SMAs in civil structures.

Like many other metals and alloys, SMAs have more than one crystal structure. This is called polymorphism. The prevailing crystal structure or phase in polycrystalline metals depends on both temperature and external stress [1]. The high temperature phase is called austenite, whereas the low temperature phase is referred to as martensite.

The reversible switching between the phases in SMAs and the associated changes in the electric, thermal and above all the mechanical properties allow for ingenious applications in enhanced, smart or adaptive civil engineering structures.

To date about 30 alloys are reported to show a shape memory effect. Hence they belong to the group of SMAs. Examples are given in Table 1. However, not all of them have the potential for being used in civil structures. This is due to the special mechanical properties required, the specific temperature conditions in civil structures and last but not least the costs involved.

An introduction to the material behaviour of SMAs is given in the following sections. Starting with some general statements, Ni-Ti and Fe-Mn-Si based alloys will be described in more detail. Furthermore, an overview of applications in civil engineering is given as are named limitations in using SMAs in civil engineering structures. Lastly, new ideas are discussed.

\section{SOME BASICS ON SHAPE MEMORY ALLOYS}

\subsection{Material phenomena}

The Shape memory alloys are mostly known for their ability to revert to their initial shape upon heating until they enter their high temperature phase after having been deformed (pseudoplastic deformations) in the low temperature phase (Figs. 1c, d). This is called shape memory effect (also referred to as 'one way shape memory effect' or pseudoplasticity). A

\begin{tabular}{|l|l|l|}
\hline \multicolumn{3}{|c|}{ Table 1 - Some alloys exhibiting shape memory effect } \\
\hline Alloy & Composition [atomic \% & Transformation \\
\hline $\mathrm{Cu}-\mathrm{Al}-\mathrm{Ni}$ & $28-29 \mathrm{Al}, 3.0-4.5 \mathrm{Ni}$ & TE=-thermoelastic \\
\hline $\mathrm{Cu}-\mathrm{Sn}$ & $15 \mathrm{Sn}$ & $\mathrm{TE}$ \\
\hline $\mathrm{Cu}-\mathrm{Zn}$ (brass) & $38.5-41.5 \mathrm{Zn}$ & $\mathrm{TE}$ \\
\hline $\mathrm{Cu}-\mathrm{Zn}-\mathrm{X}$ & $(\mathrm{X}=\mathrm{Si}, \mathrm{Al}, \mathrm{Ga}, \mathrm{Sn}) \mathrm{few} \% \mathrm{X}$ & $\mathrm{TE}$ \\
\hline Fe-Cr-Ni-Mn-Si & $9 \mathrm{Cr}, 5 \mathrm{Ni}, 14 \mathrm{Mn}, 6 \mathrm{Si}$ & non-TE \\
\hline Fe-Mn-Si & $28-33 \mathrm{Mn}, 4-6 \mathrm{Si}$ & non-TE \\
\hline Fe-Ni-C & $31 \mathrm{Ni}, 0.4 \mathrm{C}$ & non-TE \\
\hline Fe-Ni-Co-Ti & $33 \mathrm{Ni}, 10 \mathrm{Co}, 4 \mathrm{Ti}$ & TE \\
non-TE \\
\hline Fe-Ni-Nb & $31 \mathrm{Ni}, 10 \mathrm{Co}, 3 \mathrm{Ti}$ & non-TE \\
\hline $\mathrm{Mn}-\mathrm{Cu}$ & $31 \mathrm{Ni}, 7 \mathrm{Nb}$ & \\
\hline $\mathrm{Ni}-\mathrm{Al}$ & $5-35 \mathrm{Cu}$ & $\mathrm{TE}$ \\
\hline $\mathrm{Ni}-\mathrm{Ti}$ & $36-38 \mathrm{Al}$ & $\mathrm{TE}$ \\
\hline $\mathrm{Ni}-\mathrm{Ti}-\mathrm{Cu}$ & $49-51 \mathrm{Ni}$ & $\mathrm{TE}$ \\
\hline \multicolumn{2}{|c|}{$\mathrm{Taken}$ from [4] } \\
\hline
\end{tabular}

mechanical stress occurs in the material if the deformation recovery is restrained. This recovery stress can be used for introducing forces in structures.

Another important phenomenon is the so-called superelasticity (also referred to as pseudoelasticity) in which the phase transformation from austenite to martensite occurs just by increasing the external stress and without changing the temperature (Figs. 1e, f). The alloy undergoes the retransformation to the austenitic state automatically by unloading the stress. The stress-strain curve for the superelasticity shows a distinctive plateau and a hysteresis.

A further characteristic of SMAs is their extraordinary damping capacity, which will be discussed later in more detail.

Finally, the so called 'two way shape memory effect' should be mentioned. This effect describes the ability of some alloys to remember two different shapes depending
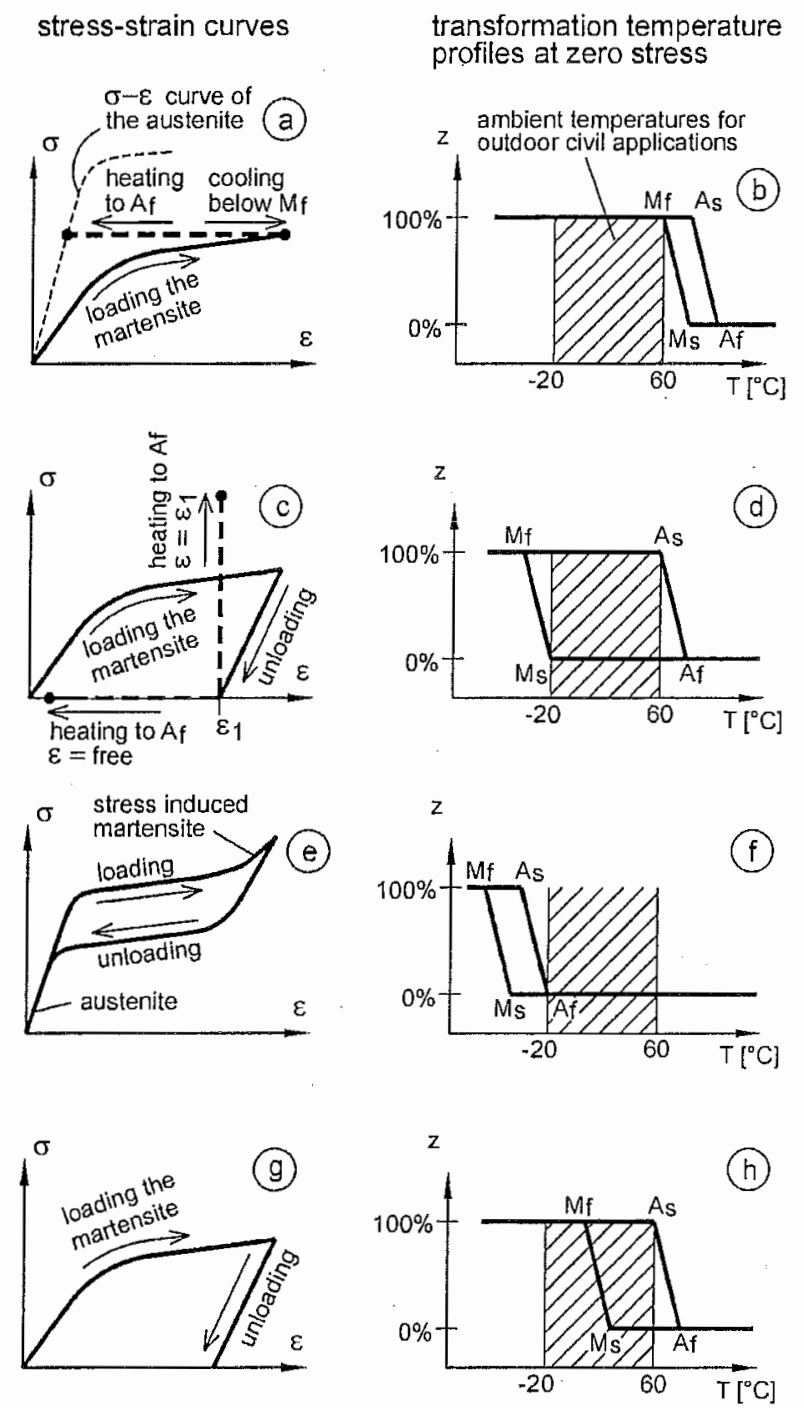

Fig. 1 - Principle stress strain curves of shape memory alloys and associated transformation temperature profiles in terms of the martensitic phase fraction, for actuator-like change of strain and stiffness against a constant force $(a, b)$, shape memory effect in the cases of free recovery and constrained recovery (c, d), superelasticity $(\mathrm{e}, \mathrm{f})$ and martensitic damping $(\mathrm{g}, \mathrm{h})$. 
on the current temperature. In order to achieve this effect a special thermomechanical training is required.

Consolidated information on the behaviour of SMAs can be found for example in [2,3] and more recently in [4-6].

\subsection{Transformation temperatures and ambient temperature}

In the absence of heating or cooling, the SMA is at ambient temperature. This temperature defines the phase state at which the alloy is stable without thermal actuation and which phase changes can be expected under thermal actuation and mechanical loading. For outside applications in civil structures we can assume the ambient temperature to lie between $-20^{\circ} \mathrm{C}$ in winter and $60^{\circ} \mathrm{C}$ under extreme solar radiation in summer. Alternative limits for this range can be relevant for indoor applications or for special climatic conditions. Typical material phenomena with their related transformation temperature profiles are given in Figs. $1 b, d, f$ and $h$. In these figures we use the martensitic phase fraction $z$ as a function of temperature. This can be useful for the description of the teinperature-dependent material properties. The parameter $\mathrm{z}$ describes the phase state on the scale from 0 to $100 \%$ of martensite amount. $M_{s}$ and $M_{f}$ stand for the start and finish temperatures of the transformation from the austenitic to the martensitic phase. Instead of austenite the term 'parent phase' can also be used. The values of $A_{s}$ and $A_{f}$ represent the start and finish temperatures of the re-transformation to the austenitic phase.

The transformation temperatures for different kinds of SMAs can vary considerably. They are strongly dependent on the composition of the alloy, the thermomechanical treatment during processing as well as on the value and manner of mechanical loading. For example, the transformation temperatures increase on rising external stresses (Fig. 11). This is important to consider if the phase state has to be guaranteed under a certain mechanical load. The number of the load cycle or the loading rate can also have an effect on the transformation temperatures.

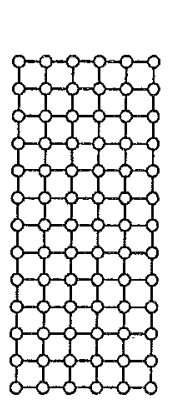

(a)

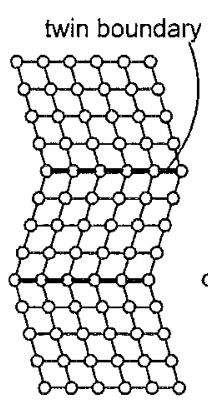

(b)

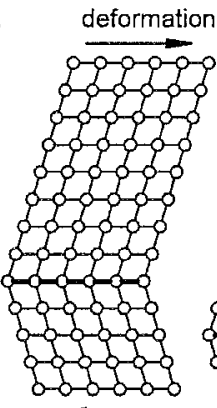

(c)

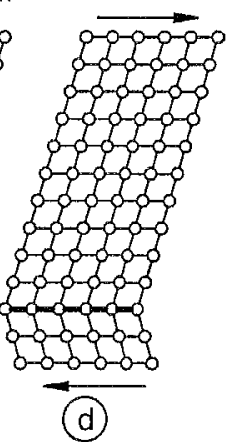

Fig. 2 - Illustration of formation and deformation of martensite in a thermoelastic SMA: austenitic crystal structure at $\mathrm{T}>\mathrm{M}_{\mathrm{s}}(\mathrm{a})$, selfaccommodated martensite when cooled below $\mathrm{M}_{\mathrm{f}}(\mathrm{b})$, reorientation of the twin variants when deformed at $T<M_{f}(c)$, moving of the twin boundaries and formation of monovariant martensite at $\mathrm{T}<\mathrm{M}_{\mathrm{f}}(\mathrm{d})$.

\subsection{Yield stresses and deformation behaviour}

The Young's modulus as a parameter for stiffness is a function of stress and strain. When working with SMAs we have to consider the actual phase state as well.

The stiffness of the austenitic phase before yielding is usually higher than that of the martensitic phase before yielding. The yield stress of the austenitic state in SMAs is higher than that of the martensitic state, unless the thermal situation of the alloy permits the formation of stress induced martensite. The yield stress of the austenite in the latter case marks the beginning of the stress induced rearrangement of the crystal structure and is associated with low stiffiness and large strains.

As in superelastic alloys, austenite is the stable phase at ambient temperature (Fig. 1f), we have a strong driving force to restore the austenite automatically after lowering the stress again. With regard to technical applications this return to zero stress and zero strain is also called recentering (Fig. 1e). Some alloys which exhibit superelastic properties show a slight increase in stiffiness once the stress induced martensitic phase transformation is completed. Stiffness continues to increase until an irreversible plastic slip and finally the break occurs. Superelasticity is present for tension and compression (Fig. 3b)

If martensite is the stable phase at ambient temperature, we have a high pseudoplastic deformability after yielding begins (Figs. la and $1 \mathrm{~g}$ ). A condition for this is the preceding formation of highly movable boundaries on an atomic scale during the martensitic transformation from austenite to martensite.

This can be accomplished for instance by the self accommodation of martensite variants in the form of a twin-like pattern. The twin boundaries can be easily sheared and moved (referred to as detwinning), which leads to a very high deformability without any real slip in terms of damage to the material (Fig. 2). This behaviour appears on both tension and compression, though the stiffness and the yield stress are higher for compression [7]. A plastic strain remains in the martensite when being pseudoplastic deformed and unloaded.

\subsection{Damping properties of SMAs}

Damping, in a technical context, stands for the conversion of mechanical energy to thermal energy and therefore for the ability to reduce movements or vibrations of a structure. One main process for this is friction, either in the form of external friction between parts of a damping mechanism or in the form of internal friction of the material of a damping part.

As internal friction in SMAs is comparatively high, they have a very good damping capacity. There are several reviews on the damping characteristics of SMAs available $[8,7,9]$.

The high internal friction is mainly based on two separate mechanisnıs. Whichever mechanism occurs is dependent on the stable phase state at ambient temperature and zero stress.

Firstly, if martensite is the stable phase, we have the gradually reorientation of martensite variants when loaded 
above the yield stress. This effect is illustrated in Figs. $1 \mathrm{~g}$ and 2. It is possible to achieve a wide stress-strain hysteresis when cycling with opposite force directions (Fig. 3a). The area, enclosed by the stress-strain curve, is equivalent to the amount of the dissipated energy.

Secondly, the superelastic behaviour of some SMAs exhibits good damping capacity as well. Reason for this is the necessary energy for the phase transformations, which is responsible for the hysteresis in the stress-strain behaviour. The movement of austenite-martensite interfaces and interfaces between martensite variants contribute relevant to the damping effect. The area enclosed by the loading and unloading path of the stress-strain curve corresponds to the dissipated energy (Fig. 3b).

A self-heating of the material and thus a change in behaviour can be a problem for higher strain rates. This is mainly dependent on the heat transfer to the environment and also on the shape and section of the shape memory parts. Cyclic loading can lead to a decrease on the upper plateau and increase the lower plateau of the stress-strain curve.

Due to the numerous influences on the material behaviour of SMAs, such as thermal situation, the loading rate, the strain amplitude, the number of cycles and the geometry of the shape memory parts, it is not easy to point out general values for the damping capacity. The following formula for the specific damping capacity (SDC) can be found in the literature [8].

$$
S D C=\frac{\Delta W}{W}
$$

where $\Delta W$ is the dissipated energy and $W$ the applied energy. For some values of SDC see Table 2.

\subsection{Fatigue resistance of SMAs}

Apart from corrosion, fatigue is an issue when long time operation is intended. Fatigue is of particular importance under cyclic loads or in case when actuators are being applied. When looking at fatigue behavior of SMAs we need to distinguish between structural fatigue (also referred to as classical mechanical fatigue) and functional fatigue (also referred to as shape memory fatigue) $[10,11]$. Structural fatigue is the accumulation of microstructural defects as well as formation and growth of surface cracks until the material finally ruptures. Functional fatigue is the gradual degradation of either shape memory effect or damping capacity by microstructural changes. The latter is associated with modification of the stressstrain-curve under cyclic loading. Transformation temperatures are affected as well.

Numerous factors like temperature, type of loading, alloy composition, specimen size, microstructure and surface quality influence the fatigue resistance of SMAs. Some prerequisites for high fatigue resistance are named in the following: A high mechanical strength of austenite and

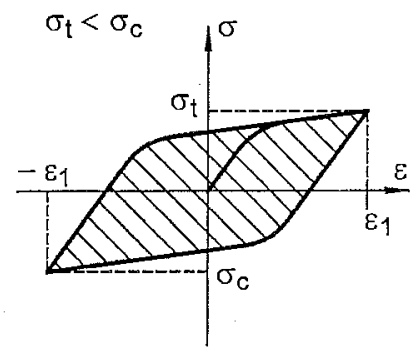

(a)

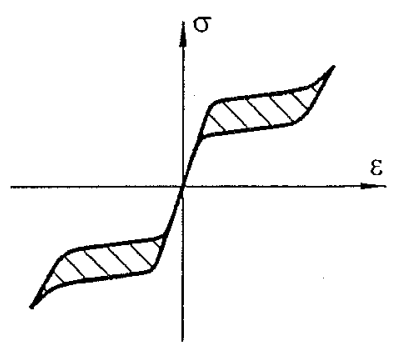

(b)
Fig. 3 - Stress-strain curves for cyclic loading for martensitic conditions at $\mathrm{T}<\mathrm{A}_{s}$ (a) and for the superelastic behaviour (b). The hatched areas correspond to the dissipated energy.

\begin{tabular}{|c|c|c|c|c|c|}
\hline \multicolumn{6}{|c|}{ Table 2 - Property values of selected shape memory alloys } \\
\hline Property & unit & $\mathrm{Ni}-\mathrm{Ti}$ & $\mathrm{Cu}-\mathrm{Zn}-\mathrm{Al}$ & $\mathrm{Cu}-\mathrm{Al}-\mathrm{Ni}$ & \begin{tabular}{|c|}
$\mathrm{Fe}-\mathrm{Mn}-$ \\
$\mathrm{Si}-\mathrm{Cr}$ \\
\end{tabular} \\
\hline $\begin{array}{l}\text { Young's modulus } \\
\text { austenite } \\
\text { martensite }\end{array}$ & $\mathrm{GPa}$ & $\begin{array}{c}70-98 \\
27\end{array}$ & $\begin{array}{c}70-100 \\
70 \\
\end{array}$ & $\begin{array}{c}80-100 \\
80 \\
\end{array}$ & $140(1)^{d}$ \\
\hline $\begin{array}{c}\text { yield strength } \\
\text { austenite } \\
\text { martensite } \\
\end{array}$ & $\mathrm{MPa}$ & $\begin{array}{c}100-800 \\
50-300 \\
\end{array}$ & $\begin{array}{c}150-350 \\
80-300 \\
\end{array}$ & $\begin{array}{l}150-300 \\
150-300 \\
\end{array}$ & $\sim 200(1)$ \\
\hline $\begin{array}{l}\text { ult. tensile strength } \\
\text { austenite } \\
\text { inartensite }\end{array}$ & $\mathrm{MPa}$ & $\begin{array}{l}800-1500 \\
700-2000 \\
\end{array}$ & $\begin{array}{l}400-900 \\
700-800 \\
\end{array}$ & $\begin{array}{c}500-1200 \\
1000-1200\end{array}$ & $650(1)$ \\
\hline $\begin{array}{l}\text { elongation at failure } \\
\text { austenite } \\
\text { martensite. }\end{array}$ & $\%$ & $\begin{array}{l}15-20 \\
20-60 \\
\end{array}$ & $10-15$ & $8-10$ & $29(1)$ \\
\hline recovery strain & $\%$ & 8 & 3.5 & 2 & $3.4(3)$ \\
\hline $\begin{array}{l}\text { max. recovery } \\
\text { stress }\end{array}$ & $\mathrm{MPa}$ & $600-900$ & $400-700$ & $300-600$ & $400(3)$ \\
\hline $\begin{array}{l}\text { superelastic energy } \\
\text { storage }\end{array}$ & Joule/g & 6.5 & 1.8 & & non \\
\hline $\begin{array}{l}\text { specific damping } \\
\text { capacity (SDC) }\end{array}$ & $\%$ & $15-20$ & $30-85$ & $10-20$ & - \\
\hline $\begin{array}{l}\text { fatigue strength } \\
N=10^{6}\end{array}$ & $\mathrm{MPa}$ & 350 & 270 & 350 & - \\
\hline resistivity ${ }^{b}$ & $\Omega \mathrm{m} \cdot 10^{-6}$ & $0.5-1.1$ & $0.07-0.13$ & $0.1-0.14$ & $\begin{array}{c}1.0-1.3 \\
(2)\end{array}$ \\
\hline $\operatorname{cost}_{\text {ratios }}{ }^{c}$ & & $10-100$ & $1-10$ & $2-20$ & - \\
\hline 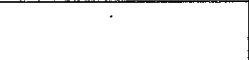 & \multicolumn{4}{|c|}{ Taken from [4] } & \\
\hline Reference & \multicolumn{5}{|c|}{$\begin{array}{l}\text { (1) measurements with } \mathrm{Fe}-27 \% \mathrm{Mn}-6 \mathrm{Si}-5 \mathrm{Cr} \text { at } 22^{\circ} \mathrm{C} \\
\text { (2) data given by the material supplier } \\
\text { (3) from [21 ] for } \mathrm{Fe}-28 \% \mathrm{Mn}-6 \mathrm{Si}-5 \mathrm{Cr}-1.5 \mathrm{VN} \text { (mass } \% \text { ) }\end{array}$} \\
\hline \multicolumn{6}{|c|}{$\begin{array}{l}\text { a dependent on frequency and amplitude } \\
\text { b varies for martensite and austenite } \\
\text { c varies greatly with shape, required quantities, etc. } \\
\text { d higher values was given by the material supplier }\end{array}$} \\
\hline
\end{tabular}

martensite is beneficial. Alloys with a relatively soft austenite, like prevalent in iron-based SMAs, show a high fatigue [11]. The melting temperature should be high in order to avoid microstructural changes by diffusion processes. This is for instance not the case in all copperbased SMAs [10]. The exploited strains must be small when aiming at a high cycle number [11]. 


\subsection{Modelling}

An important prerequisite for the introduction of SMAs into the design process is the further development of calculation models. These models must represent the highly complex behaviour of SMAs. For instance, the thermal effects induced by latent heat and friction in applications with cyclic loads or high strain rates need to be considered. This is necessary because the mechanical and functional properties of SMAs are strongly dependent on temperature. Even the fatigue resistance of SMAs seems to be connected with temperature $[11,12]$.

A number of models already exist. An overview of modelling can be found in $[13,9]$. More specific information can be found in [14] and [15], among others.

\section{BEHAVIOUR OF SELECTED SMA OF SIGNIFICANCE FOR CIVIL ENGINEERING APPLICATIONS}

\subsection{Nickel-titanium-based thermoelastic alloys}

The shape memory effect in a $\mathrm{Ni}-\mathrm{Ti}$ (nickel-titanium) alloy was first reported in 1963 by Buehler et al. [6]. Binary. $\mathrm{Ni}-\mathrm{Ti}$ as well as ternary Ni-Ti-X alloys are certainly the most researched types of SMAs (X stands for possible additional alloying elements). These alloys can change between austenite and martensite and vice versa just by changing temperature. Therefore they belong to the group of thermoelastic alloys.

Reviews on Ni-Ti alloys can be found in $[3,16]$ and with special regard to fatigue in [10]. Some property values of Ni-Ti are shown in Table 2.

The crystal lattice of Ni-Ti is body centered cubic (bcc) in the austenite phase and face centered cubic (fcc) in the martensite phase (Fig. 4). A composition with about 49 to 51 (atomic) \% Ni in the binary alloy is appropriate in order to avoid precipitates of undesirable intermetallic phases of nickel and titanium [17]. The composition can be adjusted in order to use the alloy in actuator, superelastic, shape memory and martensite-damping applications. Such applications can then be used at the usual ambient temperatures in civil structures. Self-accommodated martensite is formed in $\mathrm{Ni}$-Ti when cooling the material below $\mathrm{M}_{\mathrm{s}}$. This is an important prerequisite for an excellent pseudoplastic deformability (Fig. 2). Strains up to $8 \%$ can then be recovered by shape memory effect. Recovery stresses up to $900 \mathrm{MPa}$ for constrained recovery are possible.

Due to its excellent deformation behaviour and a very good fatigue resistance, $\mathrm{Ni}-\mathrm{Ti}$ was successfully used in many investigations on damping. However, less expensive SMAs like $\mathrm{Cu}-\mathrm{Zn}-\mathrm{Al}$ (copper-zinc-aluminium) and $\mathrm{Cu}-\mathrm{Al}$ $\mathrm{Ni}$ (copper-aluminium-nickel) showed very good damping properties as well $[18,8]$.

The following statements for superelastic damping behaviour of usual $\mathrm{Ni}-\mathrm{Ti}$ alloys can be found in the literature [7]. Strains up to $8 \%$ for tension and $12 \%$ for torsion can be recovered. The first 1.5 to $2 \%$ of strain are.

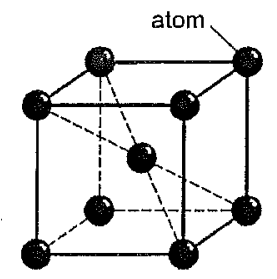

(a)

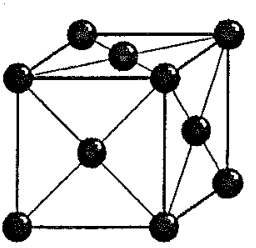

(b)

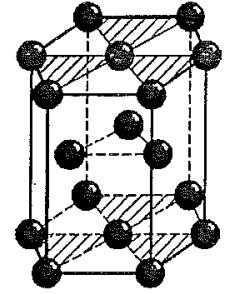

(c)
Fig. 4 - Crystal lattices: body-centered-cubic (a), face-centeredcubic (b), hexagonal close packed (c).

Hookian elasticity. Several hundreds or thousands of superelastic cycles can be carried out if the strains are limited to values of 3 to $6 \%$. Values for the superelastic energy storage are given in Table 2 .

The martensitic damping capacity of $\mathrm{Ni}-\mathrm{Ti}$ rises with increasing strains. The damping capacity decreases with the number of load cycles until approaching a stable limit [9]. First cycle effects occur; thus the modification of the stressstrain curve, in particular within the first 10 to 20 cycles [9].

The addition of $\mathrm{Cu}$ (copper) as $\mathrm{X}$ to the Ni-Ti-X system results in a very small temperature hysteresis of only a few Kelvin, which is good for actuator applications. When adding $\mathrm{Nb}$ (niobium), one can widen the temperature hysteresis up to $145 \mathrm{~K}$. This can be desirable for applications aimed at permanent recovery stress [4].

\subsection{Iron-manganese-silicon non-thermoelastic alloys}

Fe-Mn-Si-X alloys belong to the group of iron-based SMAs, which are also referred to as shape memory steels [19]. The shape memory effect in Fe-Mn-Si containing a sufficient amount of Mn was detected in 1982 by Sato et al. [20]. Since then it has attracted the interest of many material scientists as well as a growing number of civil engineers. The ratio of 60 to $65 \%$ of iron in Fe-Mn-Si-X alloys combines low costs with high strength and a high Young's modulus. Fe-Mn-Si based alloys have up to now been only suitable for the utilisation of the one-way shape memory effect.

The crystal lattice of Fe-Mn-Si is face centered cubic in the austenitic state and hexagonal close packed (hcp) in the martensitic state (Fig. 4). Although the crystal structure of ternary $\mathrm{Fe}-\mathrm{Mn}-\mathrm{Si}$ is exhibiting no notable thermoelastic properties, it is possible to bring about the formation of martensite by an external stress $[20,21]$. For this reason the cooling of the alloy below $M_{s}$ is indeed necessary in order to provide the metastable state as a prerequisite for the transformation but not a sufficient condition. The transformation occurs only after a certain external stress has been exercised. This stress is responsible for the formation of exactly one martensite variant within the hcp structure. This type of martensite formation is elementary to recover the pseudoplastic deformations upon heating above $A_{f}$. An extensive review of this is given by Kajiwara in [20] 
During the past years Fe-Mn-Si-based alloys with several additional alloying elements were developed and tested. Researchers managed to overcome the poor shape memory effect and inferior corrosion behaviour in the ternary system. With the addition of up to $10 \%$ chromium and nickel, a corrosion behaviour similar to that of stainless steel was reached [22]. Apart from that the addition of $\mathrm{Al}$, $\mathrm{C}, \mathrm{Co}, \mathrm{Cu}, \mathrm{N}, \mathrm{Nb}, \mathrm{NbC}, \mathrm{V}, \mathrm{VN}$ and $\mathrm{ZrC}$ in order to improve the shape memory can be found in the literature, e.g. in [2326]. Several treatments such as thermomechanical training, centrifugal casting, precipitation hardening and high-speed deformation aiming at improving the shape memory effect in Fe-Mn-Si-based alloys were reported [23, 27].

The alloy $\mathrm{Fe}-28 \% \mathrm{Mn}-6 \mathrm{Si}-5 \mathrm{Cr}$ (mass \%) with small amounts of $\mathrm{VN}$ or $\mathrm{NbC}$ was recently reported to show more than 300 and up to $400 \mathrm{MPa}$ stress for constrained recovery $[23,28]$. An almost complete strain recovery for a prestrain of about $3 \%$ for free recovery was measured there. $M_{s}$ in $\mathrm{Fe}-\mathrm{Mn}-\mathrm{Si}-\mathrm{Cr}$ alloys usually ranges around zero ${ }^{\circ} \mathrm{C}$. A relatively wide temperature hysteresis $A_{f}-M_{s}$ of about $160 \mathrm{~K}$ is reported [22].

Also other iron-based alloys show nearly perfect one-way shape memory effect of several percent after complex thermomechanical treatment (see Table 1). Most of them are non-thermoelastic. However the Fe-Ni-Co-Ti alloy shows a thermoelastic transformation and can have a recovery stress of up to $1000 \mathrm{MPa}$ [29]. This alloy is highly corrosion resistant. Its $\mathrm{Ms}$ lies in the range of $100^{\circ} \mathrm{C}$. Also superelasticity and twoway shape memory effect are possible [4].

\section{OVERVIEW OF APPLICATIONS IN CIVIL STRUCTURES}

\subsection{Passive vibration damping and energy dissipation}

\subsubsection{Previous research programmes}

The "Manside" project is one of the two largest research projects on SMAs in relation to civil engineering up to now. "Manside" stands for "Memory Alloys for New Seismic Isolation and Energy Dissipation Devices'. The project ran from 1995 to 1999. Research on material behaviour and modelling of SMAs was conducted. Seismic isolators and energy dissipating braces where developed, produced and lab tested. A comparison with other strategies for the attenuation of seismic vibrations was carried out. Ni-Ti was found to be the most suitable material for the damping of seismic loads. More information can be found in [30] and also on the Internet [31].

Almost at the same time, between 1996 and 1999, the "Istech" project was carried out. It was subtitled 'Shape Memory Alloy Devices for Seismic Protection of Cultural Heritage Structures'. This project focused on the development and exploration of SMA devices with superelastic behaviour with regard to the retrofitting of masonry structures. Further information on "ISTECH" can be found in [32] and the associated publications.
Within the framework of these projects two examples of retrofitting historical structures were actually realised. Some information on this will be given in the following sections.

\subsubsection{Applications of martensite damping}

Although the damping capacity of martensite is much higher than that of the superelastic phase transformation and has been known for a long time, the number of technical applications is still very low. This is probably due to the missing re-centering capability for cyclic loads. The re-centering is not necessary for impact loads. When using the material for the damping of vibrations alternately in tension and compression mode, it is always necessary to allocate rather compact parts to guarantee the stability under compression. When used in two-way bending or torsion mode, the damping effect is only activated in some regions of the section.

Different martensitic Ni-Ti SMA kernels for damping devices were designed and tested within the "Manside" project. Their capability of damping seismic vibrations in isolation devices for buildings or for the bracings of frame structures was proven [30]. Cardone et al. [33] proposed a design for bracings of multi-storey reinforced concrete (RC) frames with a martensitic $\mathrm{Ni}-\mathrm{Ti}$ adapter as the damping element. However, it could not be demonstrated clearly that martensitic Ni-Ti alloys are actually superior to classic steel bracings and superelastic SMA bracings when it comes to reduce damage of the RC-structure under earthquake loads.

While aiming for a deformation fuse Ocel et al. [34] designed and tested a partially bending resistant connection of steel beams. They connected the flanges of I-beams with martensitic Ni-Ti bolts. The opposing pairs of bolts can allow for a bending moment when being exposed only to tension and compression. Their tests worked quite well in limiting the bending moment in the steel structure. Finally the bolts buckled out and could not be fully straightened against the static load, although the shape memory effect was initiated by an external heat source.

Further examples of the use of martensite damping are available in the literature.

\subsubsection{Applications of superelasticity}

Up until now, it has been mostly the superelastic behaviour, the material phenomenon of SMAs, which has by far attracted most attention from civil engineers. Its major field of application is retrofitting structures in an earthquake suitable design. Only a brief selection can be given here.

As early as at the beginning of the 1990's basic research works in the field of damping civil structures with SMA dampers were published. Graesser and Cozzareli [35] successfully used Ni-Ti for the damping of seismic loads. Yet another work of Wittig and Cozzarelli [36] used Cu$\mathrm{Zn}-\mathrm{Al}$ for torsion, bending and tension dampers incorporated in bracings. The effectiveness of bracing systems employing superelasticity for the damping of multi-storey structures subjected to seismic loads, has been 
proved many times since then [37-39]. Cardone et al. [33] compare in their most recent work superelastic bracings of $\mathrm{RC}$-frames with classic steel bracings.

Many devices employing superelastic wires for passive damping with re-centering capability were designed and also patented e.g. [40].

One example of a real full scale application of a superelastic SMA device is the earthquake resistant retrofit of the Basilica San Francesco at Assisi, Italy [41,30]. The historic gable was connected with the main structure by devices employing SMA rods (Fig. 5). Although the device was designed to take tension and compression forces, the $\mathrm{Ni}-\mathrm{Ti}$ rods are only subjected to tension. Another project that has been executed is the earthquake resistant retrofit of the bell tower of the Church of San Giorgio, Italy (Fig. 6). Steel tendons were added to increase tilt resistance. Intermediary superelastic SMA devices act as load limiters to prevent the masonry from compression failure $[42,32]$.

DesRoches and Delemont proposed in [43] increasing the position stability of 'simply supported' bridges in earthquake regions by connecting the bearing and the bridge deck with superelastic bars (Fig. 7).

Several structure oriented calculation models were worked out. For examples refer to Wilde et al. in [44] for the modelling of a superelastic isolation of elevated highway bridges and Sun and Rajapakse in [45] for the dynamic response of a superelastic braced frame structure.
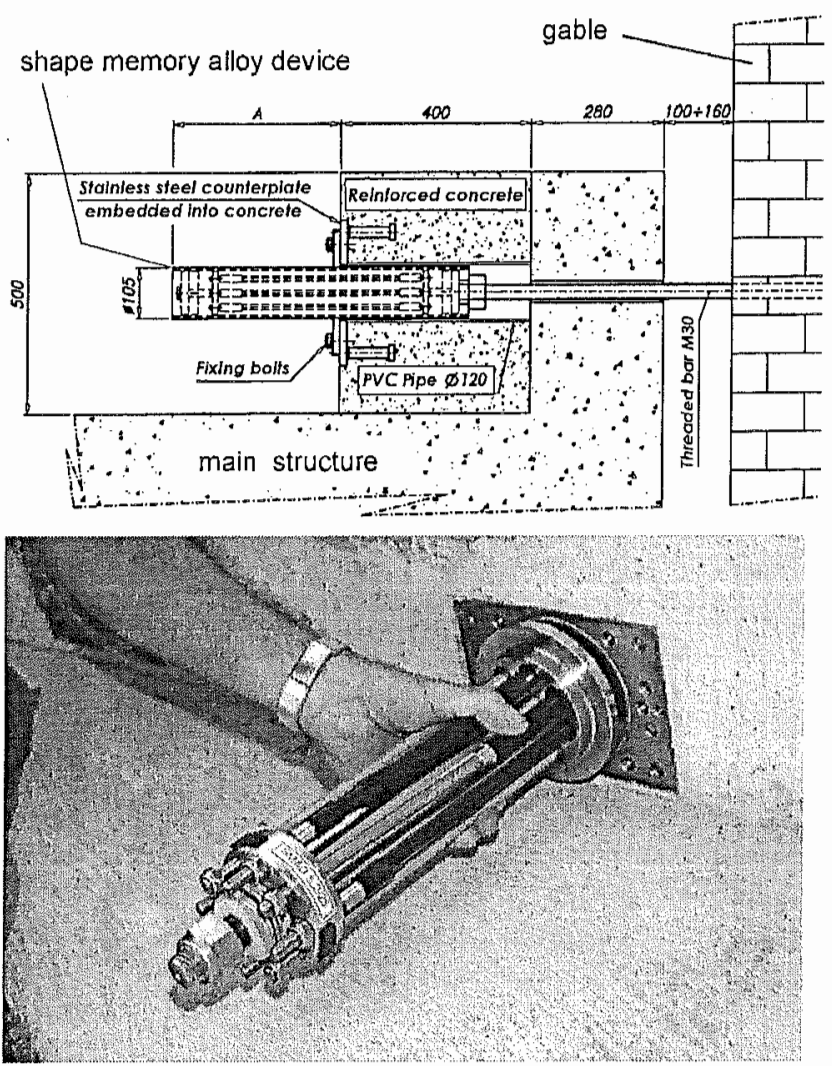

Fig. 5 - Shape memory alloy device used for the earthquake suitable connection of the historic gable and the main structure of the Basilica San Francesco in Assisi, Italy (taken from [39]).

\subsection{Concepts for active vibration control}

Several concepts for an active control of vibrations of structures by SMAs were proposed. Active vibration control offers adaptability to changing citation frequencies or to changing eigenfrequencies. The eigenfrequencies of a structure may change when the static loads or the state of the structural system changes.

One method of active damping employs the damping capacity and the tuning functionally within one SMA part. E.g. Nae et al. proposed in [46] the control of the superelastic stress-strain curve of thin SMA wires for vibrations of up to $5 \mathrm{Hertz}$. They used resistance heating and forced convection cooling for temperature control.

Another group of concepts employs SMAs in addition to conventional damper elements. Here the SMA parts are using either their ability to bring on forces or just their adaptive stiffness.

Shahin $e$ t al. presented in [47] a model for an individual bay of a multi-storey building with crossed tension-only braces. The braces were made of SMA rods and used as actuators. The damping element in their model was incorporated in the columns of the frame structure. When used un-actuated, the tendons are in martensitic state. The applied control strategy is to heat the crossing tendons alternately to the austenitic state in order to oppose the
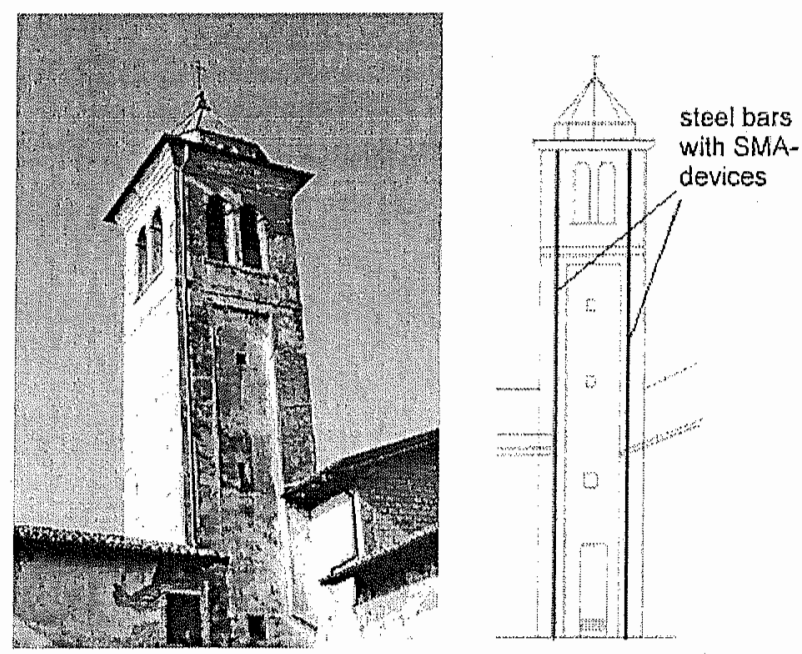

Fig. 6 - Earthquake suitabie retrofitting of the bell tower of the Church of San Giorgio, Italy, by adding steel tendons with intermediary superelastic shape memory alloy devices (taken from [40]).

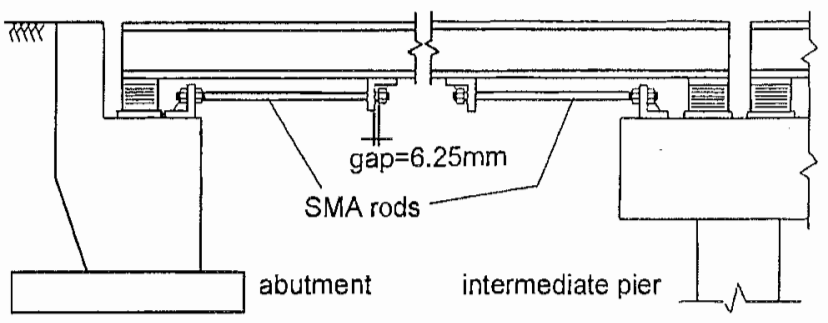

Fig. 7. - A proposal for increasing the position stability of "simply supported' bridges in earthquake regions, using superelastic shape memory rods (taken from [41]). 
displacement of the frame structure. A displacement reduction-factor of 7 was achieved by this control of the tendon stiffness. The un-actuated and thus martensitic tendon was not loaded above the martensites yield stress. Otherwise, the potential martensite variant reorientation and the corresponding large strains in tendons would be a problem for this mode of active vibration control.

A model with an adaptive spring was given by Williams at al. in [48]. The stiffness of a SMA cantilever spring was tuned by way of resistance heating. Thus the mass-ended cantilever was acting as an adjustable damping system with variable eigenfrequency. A problem of this basic concept is the drastic difference in stiffness between the phases of the alloy and the associated strong skip in eigenfrequency. In order to achieve a more insensitive or gradual change in stiffness they used a set of multiple springs that were heated gradually.

Further information about the design of SMA springs with regard to active vibration control can be found in Liang and Rogers [49].

The above concept of springs with adaptive stiffness can be used to design adaptive tuned mass dampers for civil structures. A general illustration of the idea of an adaptive tuned mass damper employing shape memory springs is presented in Figs. 8 and 9.

As the SMA part in an active vibration control system is controlled by temperature, the activation times have to be considered. This is discussed in section 5.3.

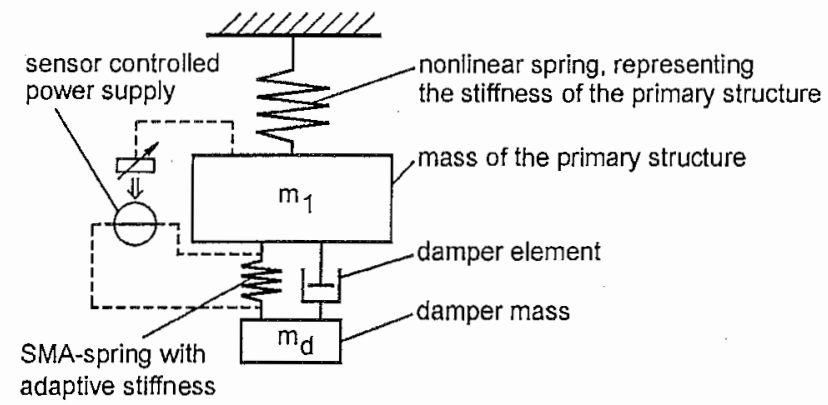

Fig. 8 - Concept for active vibration control of a structure by an adaptive tuned mass damper employing a shape memory alloy spring.

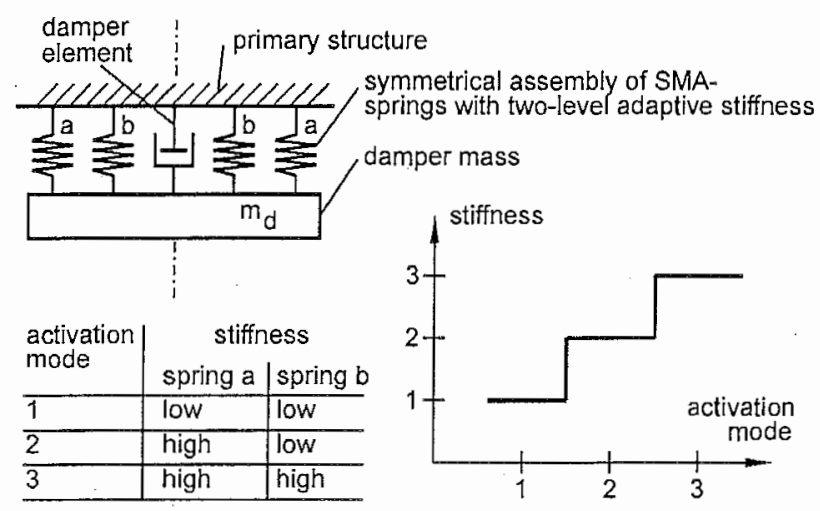

Fig. 9 - Concept for more insensitive adaptation of an adaptive tuned mass damper using an assembly of two-level stiffness shape memory alloy springs.

\subsection{Actuator applications}

An actuator is a mechanism by which a control system acts on a structure and thus changes the behaviour of the structure. Due to the shape memory effect, SMAs can function as actuators. This can be realised either by exerting forces on the structure or by changing the shape. Fig. 10 shows this functionality together with the related stress-strain curve. The control parameter of SMA actuators is temperature. The transformation temperature profile, shown in Fig. $1 \mathrm{~b}$, is imperative to provide if the SMA actuator shall return to the initial state when un-actuated. In this paper the term actuator shall only apply if repeated activation of the shape memory effect and return to the initial state takes place. Actuation must be followed by de-actuation. This condition applies as well if multiple heating cycles are used to activate the shape memory effect gradually or additionally.

To date several concepts for shape memory actuators in civil engineering have been reported $[50,51]$. Researchers often try to control prestressing forces. As prestressing force is a separate load case for the structure, its existence is only advantageous if it is opposing external loads. Prestressing alone can be the decisive load case and hence prevents engineers from building more slender and lighter structures.

Two obstacles oppose the application of shape memory actuators in civil structures. Firstly, the cost of the material and secondly the inertance of heating and cooling can limit the use.

The cost problem might be resolved if the actuator functionality can be implemented with devices of reasonable size. The aspect of thermal activation will be addressed in section 5.3 .

\subsection{Utilisation of the shape memory effect for tensioning applications}

\subsubsection{Couplings and fasteners}

Pipe couplings were the very first commercial application of SMAs. What started with Ni-Ti hydraulic line couplings for jet fighters in the 1970 's, is today also possible with low cost iron-based SMAs and for larger pipe diameters [28]. Other ideas in the field of fastening and the related application of the shape memory effect, are available in the literature. E.g. Shen et al. proposed in [52] a SMA nut for threaded connections
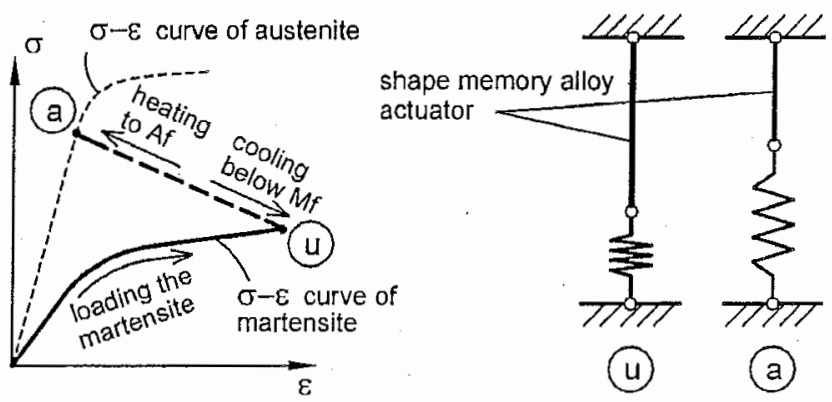

Fig. 10 - Function of an actuator and related stress-strain behaviour for the un-actuated mode (u) and the actuated mode (a). The pictured spring can represent the stiffness of a structure at which the actuator acts on. 
subjected to vibrations. The loosening of the nut is prevented by contact pressure caused by preliminary shape recovery.

\subsubsection{External tensioning}

Common reasons for retrofitting structures are deficits in load bearing capacity and the risk of large deformations due to increasing loads. If such structures are massive, they often also show cracks that lead to a decrease in durability. Adding external tensioning elements is today a well accepted strategy for countering such insufficiencies. Several materials such as steel or more recently also fibre reinforced plastics (FRP) are suitable for this task. In contrast to these materials, SMAs have the ability of being stressed without any tensioning devices, like hydraulic jacks etc. When mounted and anchored, they just need to be heated to initiate the shape memory effect. As deformation recovery is restrained, a tension force builds up.

Heating by means of electric current is relatively simple. Even if the cross section that can be heated at a time is limited by the size of the power supply, multiple tensioning elements can be easily heated consecutively. Heating by torches may be possible, but less controllable. If SMA tensioning elements are fitting to the structure, friction poses no problems as will be discussed later.

E.g. Soroushian et al. in [53] give an example of the realisation of an external posttensioning. Corrosion resistant $\mathrm{Fe}-\mathrm{Mn}-\mathrm{Si}-\mathrm{Cr}$ rods were used to enhance the shear resistance of a cracked region of a reinforced concrete bridge girder (Fig. 11). Resistance heating was applied at a current of 1000 Ampere.

\subsubsection{Prestressed fibre reinforcement in cementitious naterials}

Cementitious materials, like plaster, mortar or concrete usually show a very poor tension strength. Their low ductility is a limitation to many applications. The use of fibres as reinforcement is a very effective way of enhancing these materials. The idea of tensioning continuous fibres by shape memory effect was discussed in the literature [5456]. However, there are many questions still to be answered, in particular concerning the manufacturing of full scale members and heating technology.

\subsubsection{Shape memory alloy tendons in concrete}

Shape memory alloy rods or cables can also act as tendons in new concrete members.

Some research works on this were presented e.g. in [51, $57-60]$.

Such tendons have several advantages over conventional steel tendons. Firstly, there are no friction losses. This is due to the uniform development of the tension force along the entire length of the tendon when initiating the shape memory effect. Particularly in curved concrete members or when the tendon profile is very curved, friction losses tend to cause problems. Apart from that, there is no need for anchors when using SMA tendons. This can be an unrivalled solution for tensioning extremely thin concrete members.
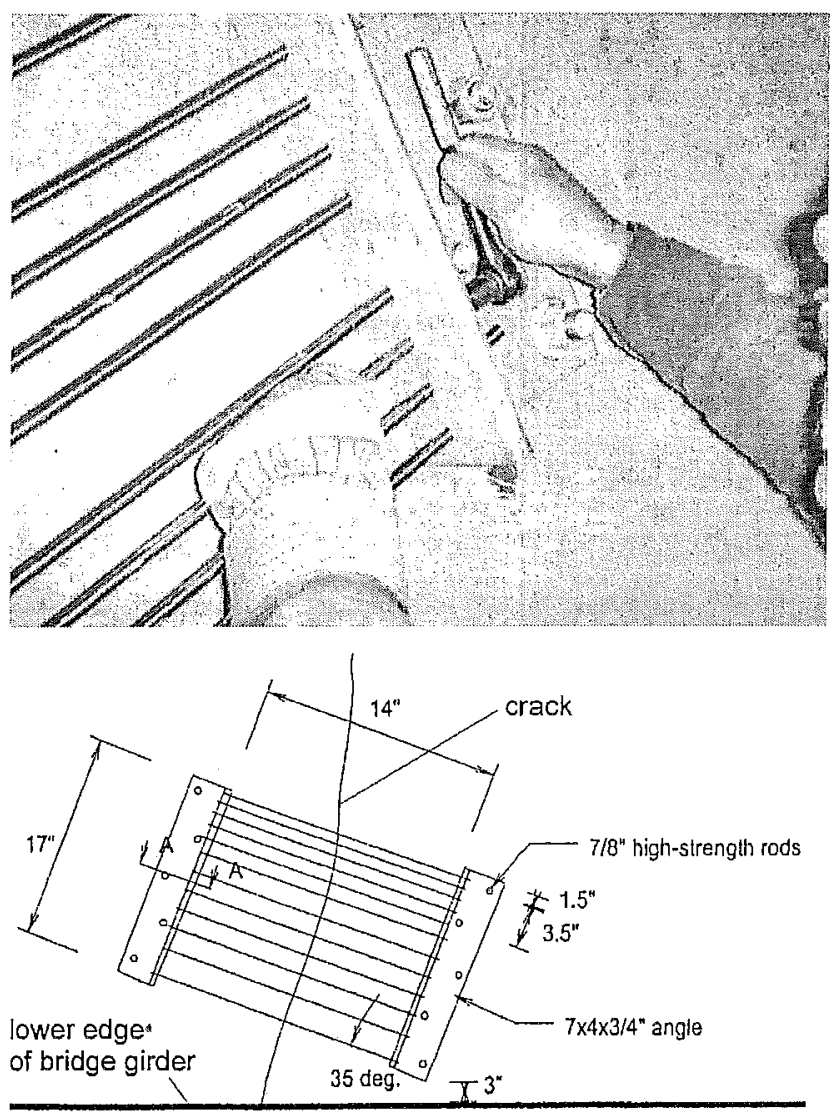

Fig. 11 - Repair of a cracked region of a highway bridge in Michigan by mounting and post-tensioning of exterior iron-based shape memory alloy elements (taken from [51]).

\subsection{Hybrid composites of shape memory alloys and plastics}

Plastics evolved into a structural material for the building industry during the past decade. They are applied in both retrofitting and new design. Especially with carbon or glass fibres reinforced plastics (CFRP, GFRP) are used for sheets and even complete beam sections. This is a motive to allude to the field of hybrid composites. Researchers aim to improve composites by adding SMA fibres [61]. However, the considered test specimen size in current research on hybrid composites is rather small.

Particularly shape memory effect is used to control the dynamic behaviour $[62,63]$ or to suppress damages in the composite system [64]. Other studies propose e.g. composite patches for damage repair of structures [65]. Here are SMA wires employed to provide a certain closure stress. An extensive overview on hybrid composites is given in [66].

\subsection{Sensors}

A sensor is a device that detects a physical condition. Shape memory alloys can work as sensors because their electrical resistance is dependent on their strain and their temperature [2]. Strains of up to $8 \%$ can be detected in a 
structure in this way [67]. It is also conceivable to detect certain temperature levels in a structure by the changing shape of a SMA sensor. A force can be exerted on the structure if this shape change is constrained. The former constellation combines sensor and actuator within one system, which is the prerequisite for a 'real' smart material.

\section{LIMITS}

\subsection{Costs}

Due to the size of civil engineering structures and the acting of relatively high forces, a large amount of material is needed compared to applications e.g. in automotive engineering or medical technology.

For this reason particularly in large scale applications low cost SMAs are badly needed. Fe-Mn-Si-X alloys are named in this article as an example of a potentially low cost SMA. However, there is a need for certain improvements as will be discussed in the following section.

In order to achieve the goal of a really low cost material, cost intensive alloying elements need to be avoided. If we take a look at commodity prices on the metal market and compare them for the constituents $\mathrm{Ni}$ and $\mathrm{Ti}$ on the one hand and $\mathrm{Fe}, \mathrm{Mn}, \mathrm{Si}, \mathrm{Cr}$ on the other hand and consider their ratio, we obtain a factor of about 8 to 12 . This means that the cost of an iron-based system could be only a small fraction of that of a high-performance $\mathrm{Ni}$-Ti system. Besides good superelasticity, Ni-Ti based alloys show an extremely good shape memory effect but the high material costs prevent it from being used more extensively [20].

Nevertheless the use of Ni-Ti-X alloys could lead to economically viable solutions. One could achieve a great effect on the behaviour of structures even if Ni-Ti's unique properties are utilised only in smaller devices or selected regions of the structure. Examples for this have been given in the above sections.

Cost ratios between $\mathrm{Ni}-\mathrm{Ti}$, and two copper-based alloys are given in Table 2 .

\subsection{Stress induced martensite in shape memory effect applications with Fe-Mn-Si-X}

The formation of stress induced martensite is necessary for superelasticity. However, the re-transformation from austenite to martensite and the associated loss in stiffness is unwanted when using shape memory effect for permanent tensioning. Therefore the austenitic phase has to be retained, even when cooling the material down to the lower limit of the ambient temperature range.

Reasons for stress induced martensite formation differ for different types of alloys. However, they are always connected with increased driving force for initiating the martensitic transformation either by increased external stress or lowered ambient temperature.

Stress induced martensite can be avoided by providing a suitable transformation temperature profile as shown in Fig. 12b. Also should the critical stress $\sigma_{c r i t}$ not be exceeded (Fig. 12a). Here, the critical stress is the stress value at

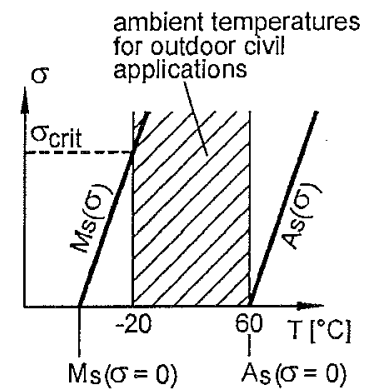

(b)

$z$ - martensitic phase fraction

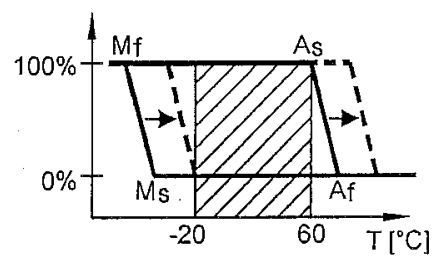

transformation temperature profile

(a)

- - at $\sigma_{\text {crit }}$
Fig. 12 - Relation between external stress and transformation temperatures in terms of the critical stress (a) and the martensitic phase fraction (b).

which the martensitic transformation starts and thereby the austenite yields.

The transformation temperature profile needed for civil applications can be provided by $\mathrm{Ni}-\mathrm{Ti}-\mathrm{X}$ alloys without problems. This is not the case for all iron-based alloys to date.

The above described Fe-Mn-Si-Cr SMAs exhibit a $M_{s}$ in the vicinity of zero ${ }^{\circ} \mathrm{C}$ and are thus metastable at ambient temperatures in civil structures. The resulting trend to build new martensite when cooled or mechanically loaded is a strong limitation for applications with permanent tensioning or changing temperatures. The following tests were performed to learn more about this.

Stress recovery tests were carried out in order to estimate the behaviour of a $\mathrm{Fe}-27 \% \mathrm{Mn}-6 \mathrm{Si}-5 \mathrm{Cr}$ SMA with regard to tensioning applications.

Ms was given by the supplier with -20 to $-25^{\circ} \mathrm{C}$ and $A_{f}$ was given to be in a range of up to $185^{\circ} \mathrm{C}$.

Firstly, the wire specimens with $1.2 \mathrm{~mm}$ diameter were heat treated at $950^{\circ} \mathrm{C}$ for $30 \mathrm{~min}$, cooled and then $2 \%$ strained at room temperature. This treatment resulted in formation of stress induced martensite, as the subsequent contraction upon heating showed. The prestrained wire was clamped at a Zwick Z010 universal testing machine inside a temperature chamber and preloaded to $15 \mathrm{~N}$ at room temperature. The temperature was raised to $210^{\circ} \mathrm{C}$ followed by cooling to room temperature $\left(22^{\circ} \mathrm{C}\right)$. Furthermore was cooled to $-20^{\circ} \mathrm{C}$ and subsequent heated again to room temperature. Fig. 13 shows force and temperature over time during this test. The superposition of shape memory behaviour with temperature elongation and contraction is to be seen clearly. The recovered force begins to drop down immediately when the temperature passes $A_{f}$. A negative slope in force was recorded while keeping the temperature constant. A reason for this can be found in the temperature inertia of the quite massive clampings and stakes. However, the force recovers due to temperature contraction when cooled. The slope of the force curve drops slightly at temperatures still over room temperature. This is supposedly due to stress induced martensite formation. Further cooling lowers the force once more. Reason again, is to be contributed to stress-induced martensite. This new transformation push is effected by both temperature contraction with according stress increase and also lower temperatures. Finally the force drops again when heated back to room temperature, which is 


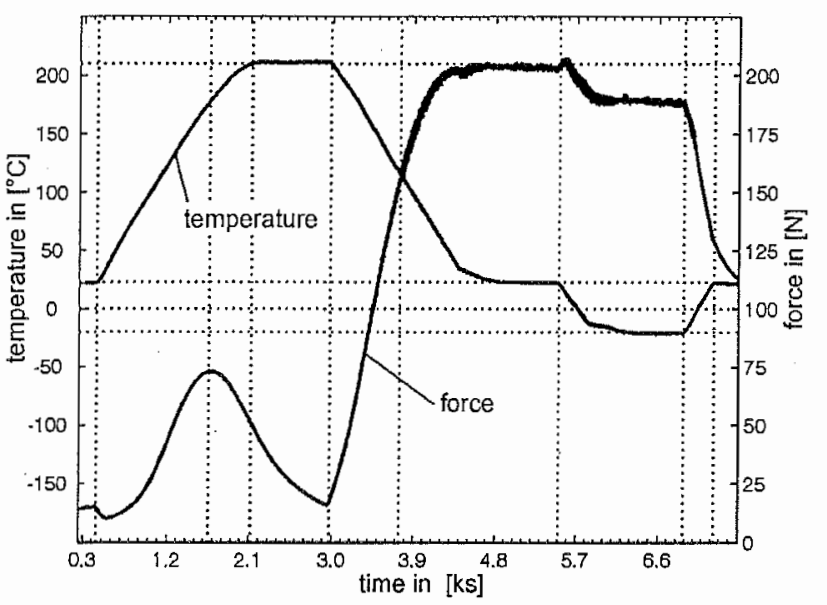

Fig. 13 - Force and temperature over time for constrained recovery of $\mathrm{Fe}-27 \% \mathrm{Mn}-6 \mathrm{Si}-5 \mathrm{Cr}$ wire.

effected again by temperature elongation. The remaining recovery force after this test cycle was $113 \mathrm{~N}$ (100 MPa).

Concluding from the above, one has to accept the need for improvements in the tested material if applications in civil engineering are intended. Nevertheless, the basic potential of generating tensioning forces with this low cost material is proven. All the more so as $\mathrm{Fe}-\mathrm{Mn}-\mathrm{Si}-\mathrm{Cr}-\mathrm{X}$ alloys with better performance was reported recently [23, 28].

\subsection{Thermal actuation and the problem of actuation time}

In order to work as actuators, SMAs have to change their phase state. Actuation time is the period of heating time needed for the SMA change from one phase state to the other. Conversely, the time needed for cooling back is referred to as de-actuation time. These periods define how fast the actuator can accomplish the adaptation to e.g. changing loads or boundary conditions. SMAs can be heated by using electric current or heat transfer. Cooling can only be achieved by heat transfer. The time for actuation is usually shorter than that of de-actuation, unless forced cooling is applied. In order to evaluate the inertance of possible actuators for civil structures, only actuation time is considered here.

Applying an electric current is the fastest way of heating up a metallic mass. However, the practicability of resistance heating is dependant on the size of the power supply and the geometry of the part. The subsequent simple equations can be employed to estimate the actuation time $t_{a}$.

$t_{a}=\frac{E_{h}}{P_{e l}}$

$E_{h}=c_{v} \cdot m \cdot \Delta T$

$P_{e I}=I^{2} \cdot R=I^{2} \cdot \frac{\rho_{e l} \cdot L}{A}$ where $E_{h}$ is the energy demand for heating the mass, $P_{\ell l}$ is the electric current, $c_{v}$ is the specific heat capacity, $\mathrm{m}$ the mass, $\Delta T$ the increase in temperature, $I$ the electric current, $\rho_{e l}$ the resistivity, $L$ the length of the actuator part and $A$ the cross section of the actuator part.

Equation (2) is improved by inserting the heat transfer to the environment $Q$. When working with SMAs, energy demand for the phase transformation $E_{p}$ needs to be considered as well.

$t_{a}=\frac{E_{h}+E_{p}}{P_{e l}-Q}$

The resulting actuation times from Equation (5) are longer than that from Equation (2).

When using resistance heating, the cross section of the actuator part is a main parameter for activation time. Due to the high forces encountered in civil engineering structures, the common cross sections are in the range of several square centimeters. A rod diameter of $12 \mathrm{~mm}\left(1.13 \mathrm{~cm}^{2}\right)$ is rather sinall.

Equation (2) was used to calculate the activation times for resistance wires with different diameters and for different currents. The length $L$ has no influence on the activation time because it affects $E_{h}$ and $P_{e l}$ equally.

Heating tests were done with $1 \mathrm{~m}$ long rods in order to verify the results of the calculation. The material used for the tests was a $\mathrm{Fe}-\mathrm{Cr}-\mathrm{Al}$ alloy without phase transformation. It has a resistivity of $139 \mu \Omega \mathrm{cm}$. This value is above the usual range of values for SMAs. Fig. 14 shows the calculated results and the data measured for a $\Delta T$ of $70 \mathrm{~K}$.

According to the simple model, it takes $23 \mathrm{~s}$ to heat a $12 \mathrm{~mm}$ rod with a current of $300 \mathrm{~A}$. To provide this current, a high capacity power supply similar to that of a welding apparatus is needed. The power supply must be very close to the actuator in order to limit the length of the thick electric cables. The measured data showed higher activation times due to heat transfer to the environment.

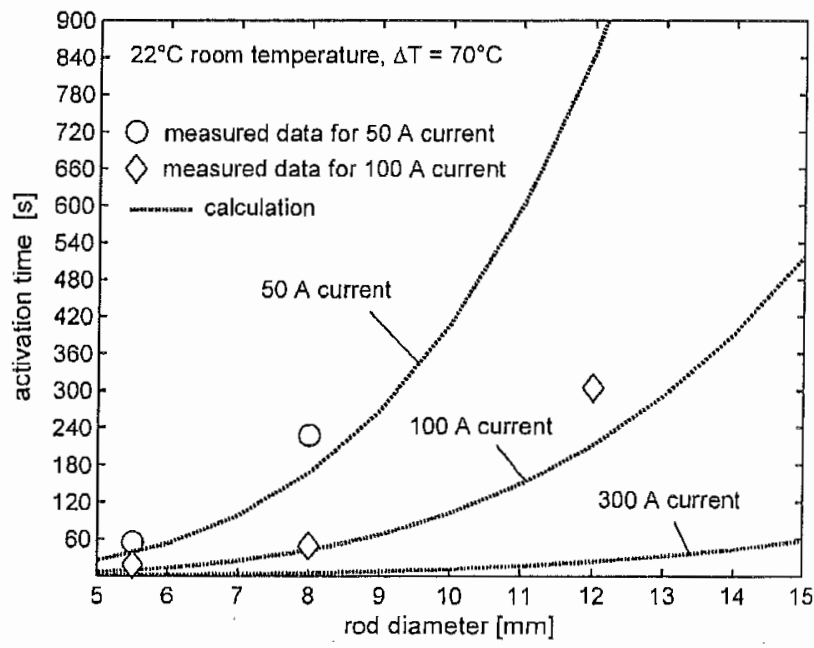

Fig. 14 - Activation times for resistance heating of rods with different diameter, calculated and measured data. 
Derived from the above calculation and measurement, the constrictions for large force SMA actuators can be given as follows. Short activation times in the range of seconds are only possible for small cross sections. With a standard power supply being used, sections that are common for civil engineering need several minutes to be actuated. A high capacity power supply with a current of several hundred Ampere can reduce activation times considerably. This may incur greater costs when setting up the actuator.

Based on the above remarks, large force SMA actuators are not appropriate for adapting to quickly changing loads. Such loads can be wind forces or live loads due to traffic. However their utilisation to adapt to slowly changing loads, like e.g. alternating temperature loading, is possible. In the latter case the expenses for providing the necessary electric power need to be considered. Keeping up the high temperature state for long periods results in increased maintenance costs of the actuation system.

The problem of cooling is another issue contributing to the inertance of shape memory actuators.

\section{NEW IDEAS}

\subsection{Active confinement}

Shape memory alloy posttensioning elements are practical for curved and angular forms. The main reason for this is the uniform development of the recovery force along the entire length of the tensioning element. This distinguishes SMAs elements for instance from the introduction of tension force by jacks at both ends of a steel cable.

An application that can take advantage of this, is the confinement of reinforced concrete members. The increase in load bearing capacity and also ductility by wrapping columns with bands or sheets of steel or FRP is well known. It was proven by many calculations and tests, e.g. [68]. It is well known that the strength of confined concrete is a function of the load.

Utilising the shape memory effect for tensioning the wrapping can enhance the effect of confinement. When we talk about tensioning the confinement with shape memory technology, the term 'Active Confinement' is being used.

Tests on SMA confined concrete members were carried out by Krstulovic-Opara et al. in [69] and [58]. They performed model scale compression tests with confined concrete cylinders. The specimens were jacketed with thin continuous $\mathrm{Ni}-\mathrm{Ti}$ wires. Stressing of the jacket was done by putting the whole specimen in an oven. The comparison between several variants of stressed and unstressed jacketing showed the potential of the Active Confinement.

The authors of the present article suggest to go on developing this concept with regard to practical needs. Concrete columns could be easily helically wrapped by continuous SMA bands. The pitch of the helix can be fitted to the aimed confinement. Fig. 15 shows the setup for the tensioning by resistance heating. Obviously, this technology is suitable in particular for retrofitting, in cases

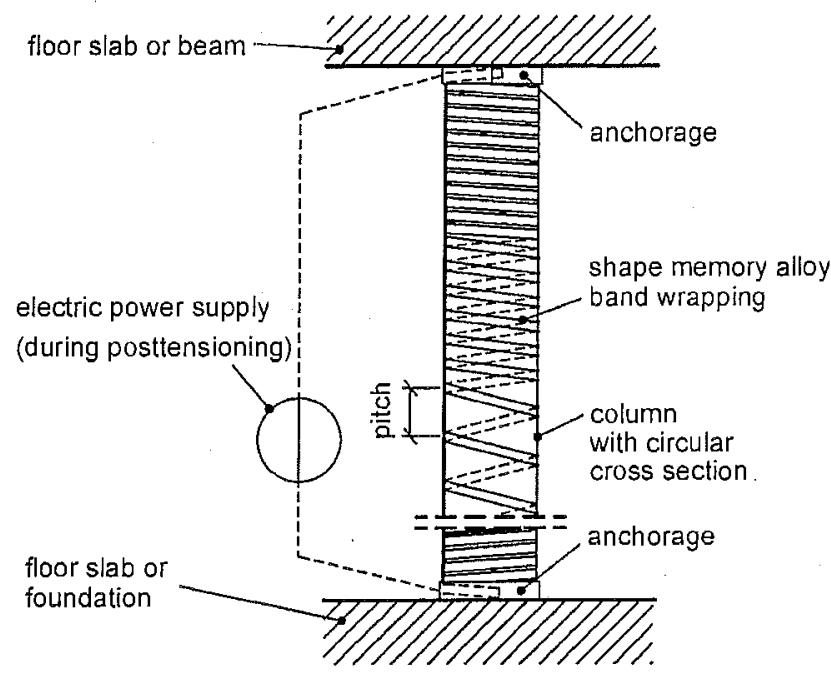

Fig. 15 - Active Confinement of a concrete column with a prestressed shape memory alloy wrapping for retrofitting purposes.

where there is only limited space for mounting, e.g. in cellars of buildings or in case of double columns. Due to the great amount of material needed, only low cost SMAs can be considered.

Calculations were carried out for a tensioned SMA jacket in comparison with steel or with CFRP jackets of equal stiffness. In this case, stiffness is the product of Young's modulus, and cross section of the wrapping. The strength values under confinement can theoretical enable very high loads at very high strains. However, only compression strains of several percent are acceptable in columns in order to prevent damage to the concrete or disadvantages to the whole structural system of a building. The load bearing capacity for small strains was hence of interest for the performed calculation.

The calculations showed a lower axial strain $\varepsilon_{\mathrm{a}}$ for the active SMA confined column compared to the steel or CFRP confined column at the same load $\sigma_{\mathrm{ca}}$ (Fig. 16). The other way around, one can say that a higher axial load can be applied at a given ultimate strain. This was true for strains up to 6 per mil in case of posttensioned SMA 2 compared to CFRP in the present calculation.

More details on the calculation method are to be published soon.

\subsection{Posttensioned tendons with immediate bond in thin concrete shells or folded plates}

Shape memory alloy tendons can be used posttensioned with immediate bond, when placed before casting and stressed after the hardening of the concrete. They are, of course, not capable of replacing conventional tendons in common bulk structures. Nevertheless, they can be very suitable for selected parts of some special structures.

For examples, thin concrete shell structures or folded concrete plates come into question. In particular the edges of such structures are typically delicate and prone to 
[61] Wu, S., 'Active fiber composites', in 'High Performance Fiber Reinforced Cement Composites (HPFRC4)', (RILEM, 2003) 153-157.

[62] Parlinska, M., Clech, H., Balta, J.A., Michaud, V., Bidaux, J.E., Manson, J.A.E. and Gotthardt, R., 'Adaptive composites with embedded shape memory alloys', J. Phys. IV 11 (2001) 197-204.

[63] Tsai, X.Y. and Chen, L.W., 'Dynamic stability of shape memory alloy wire reinforced composite beam', Composite Structures 56 (3) (2002) 235-241.

[64] Xu, Y., Otsuka, K., Yoshida, H., Hagai, H., Oishi, R., Horikawa, H. and Kishi, T., 'A new method for fabricating SMA/CFRP sinart hybrid composites', Intermetallics 10 (4) (2002) 361-369.

[65] Wang, X., 'Shape memory alloy volume fraction of prestretched shape memory alloy wire-reinforced composites for structural damage repair', Smart Mater. Struct. 11 (4) (2002) 590-595.
[66] Wei, Z.G., Sandstrom, R, and Miyazaki, S., 'Shape memory materials and hybrid composites for smart systems - Part II Shape-memory hybrid composites', J. Mater. Sci. 33 (15) (1998) 3763-3783.

[67] Aizawa, S., Kakizawa, T. and Higasino, M., 'Case studies of smart materials for civil structures', Smart Mater. Struct. 7 (5) (1998) 617-626.

[68] Teng, J.G., Chen, J.F., Smith, S.T. and Lam, L., 'FRPStrengthened RC Structures' (Wiley, UK, 2002).

[69] Krstulovic-Opara, N. and Thiedeman, P.D., 'Active confinement of concrete members with self-stressing composites', ACr Materials Journal 97 (3) (2000) 297-308.

[70] Moser, K., Bergamini, A., Christen, R. and Czaderski, C., 'Feasibility of concrete prestressed by shape memory alloy short fibres' Mater. Struct. 38 (279) (2005) 593-600. 


\begin{tabular}{l|l|l|l|l|l} 
& Unit & Steel & CFRP & SMA 1 & SMA 2 \\
\hline $\begin{array}{l}\text { Youngs modulus } \\
\text { of jacket }\end{array}$ & $\mathrm{MPa}$ & 210.000 & 240.000 & 130.000 & 170.000 \\
\hline thickness of jacket & $\mathrm{mm}$ & 2 & 1.75 & 3.23 & 2.47 \\
\hline yield stress of jacket & $\mathrm{MPa}$ & 240 & - & 190 & 400 \\
\hline prestress of jacket & $\mathrm{MPa}$ & - & - & 190 & 340
\end{tabular}

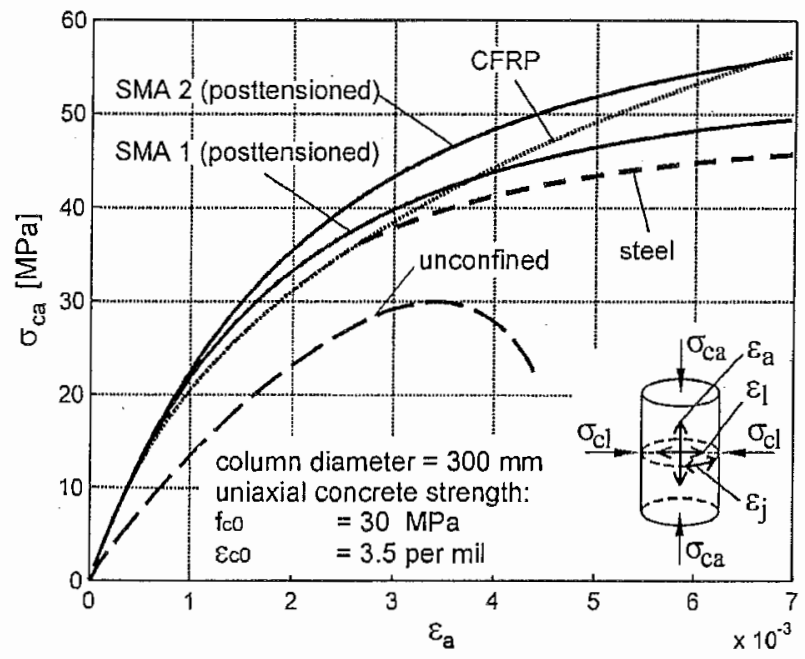

Fig, 16 - Comparison of stress-strain curves for a circular concrete column with different confinement materials. The jacket is assumed to cover the surface completely.

stability failure. SMA tendons can provide the possibility to posttension these edges. The advantages of using tendons with immediate bond in concrete were already mentioned in section 4.4.4 in this article. This technology could allow engineers to abstain from designing edge thickenings as a solution for the stability problem.

Another issue is the good corrosion behaviour of several SMAs. This feature is very profitable for the utilisation of SMA tendons in thin concrete members with low concrete cover.

Finally, it remains to be mentioned that such large scale applications depend on the improvement of potential low cost SMAs as discussed in section 5.

\subsection{Short fibres}

A completely new concept for the use of fibres in civil engineering is introduced in the article of Moser, Bergamini et al. [70] in this issue. Their promising concept utilises short fibres made of SMAs to prestress cementitious materials (pat. pending).

\section{ACKNOWLEDGEMENTS}

The authors appreciate the support of the Structural Engineering Research Laboratory at Empa - Materials Science and Technology, Switzerland and the Faculty of Civil Engineering at the Bauhaus-University Weimar,
Germany for this project. The authors would also like to thank Awaji Sangyo for providing iron-based SMA material.

\section{REFERENCES}

[1] Callister, W.D., Materials Science and Engineering: An Introduction', $6^{\text {th }}$ Edn. (Wiley, New York, 2003).

[2] Funakubo, H., 'Precision Machinery and Robotics, Vol. 1 Shape Memory Alloys' (Gordon and Breach, 1987).

[3] Duerig, T.W, 'Engineering Aspects of Shape Memory Alloys', (Butterwortl-Heinemann, London, 1990).

[4] Otsuka, K. and Wayman, C.M., 'Shape Memory Materials' (Cambridge University Press, 1999).

[5] Humbeeck, J.V., 'Shape memory alloys: A material and a technology', Adv. Eng. Mater. 3 (11) (2001) 837-850.

[6] Otsuka, K. and Kakeshita T., 'Science and technology of shape-memory alloys. New developments', Mrs Bulletin 27 (2) (2002) 91-100.

[7] Hodgson, D.E., 'Damping applications of shape-memory alloys', in 'Materials Science Forum' 394-395 (Trans Tech Publications, Zürich-Uetikon, 2002) 69-74.

[8] Humbeeck, J.V., 'The high damping capacity of shape memory alloys', Z. Metallkd. 86 (3) (1995) 176-183.

[9] Saadat, S., Salichs, J., Noori, M., Hou, Z., Davoodi, H., Baron, I., Suzuki, Y. and Masuda, A., 'An overview of vibration and seismic applications of NiTi shape memory alloy' Smart Mater. Struct. 11 (2) (2002) 218-229.

[10] Eggeler, G., Hornbogen, E., Yawny, A., Heckmann, A. and Wagner, M., 'Structural and functional fatigue of NiTi shape memory alloys' Mater. Sci. Eng., A 378 (1-2) (2004) 24-33.

[11] Hornbogen, E., 'Review: Thermo-mechanical fatigue of shape memory alloys', J. Mater. Sci. 39 (2) (2004) 385-399.

[12] Wagner, M., Sawaguchi, T., Kausträter, G., Höffken, D. and Eggeler, G., 'Structural fatigue of pseudoelastic NiTi shape memory wires', Mater. Sci. Eng., A 378 (1-2) (2004) 105-109.

[13] Auricchio, F., Faravelli, L., Magonette, G. and Torra, V., 'Shape Memory Alloys, Advances in Modelling and Applications' (International Center for Numerical Methods in Engineering, Barcelona, 2001)

[14] Matsuzaki, Y. and Naito, H., 'Macroscopic and microscopic constitutive models of shape memory alloys based on phase interaction energy function, A review', J. Intell. Mater. Syst. Struct. 15 (2) (2004) 141-155.

[15] Liang, C. and Rogers, C.A., 'One-dimensional thermomechanical constitutive relations for shape memory materials' J. Intell. Mater. Syst. Struct. 8 (1997) 285-302.

[16] Otsuka, K., Xu, Y. and Ren, X., 'Ti-Ni-based shape memory alloys as smart materials', in 'Thermec2003', Pts 1-5, (Trans Tech Publications, Zurich-Uetikon, 2003) 251-258.

[17] Melton, K.N., 'Ni-Ti based shape memory alloys', in 'Engineering Aspects of Shape Memory Alloys' (Butterworth-Heinemann, London, 1990) 21-35.

[18] Huang, W., 'On the selection of shape memory alloys actuators', Mater. Des. 23 (1) (2002) 11-19.

[19] Tamarat, K., Stambouli, V., Bouraoui, T. and Dubois, B., 'Structural study of Fe-Mn-Si and Fe-Mn-Cr shape memory steels', J. Phys. IV 1 (C4) (1991) 347-353.

[20] Kajiwara, S., 'Characteristic features of shape memory effect and related transformation behavior in Fe-based alloys', Mater. Sic. Eng., A 273-275 (1999) 67-88.

[21] Sato, A., Yamaji, Y. and Mori, T., 'Physical properties controlling shape memory effect in Fe-Mn-Si alloys', Acta Metall. 34 (2) (1986) 287-294. 
[22] Li, H.J. and Dunne, D., 'New corrosion resistant iron-based shape memory alloys', ISIJ Int. 37 (6) (1997) 605-609.

[23] Farjami, S., Hiraga, K., and Kubo, H., 'Shape memory effect and crystallographic investigation in VN containing Fe- $\mathrm{Mn}-\mathrm{Si}$ Cr alloys', Mater. Trans, 45 (3) (2004) 930-935.

[24] Lin, C., Gu, N., Liu, Q. and Wen, C., 'Research on low temperature relaxation characteristics in Fe- Mn-Si-based SMA', J. Phys. IV 112 (2003) 377-380.

[25] Baruj, A., Kikuchi, T., Kajiwara, S. and Shinya, N., 'Improved shape memory properties and internal structures in $\mathrm{Fe}-\mathrm{Mn}-\mathrm{Si}$ based alloys containing $\mathrm{Nb}$ and C', J. Phys. IV 112 (2003) 373-376.

[26] Yakovenko, P.G., Söderberg, O., Ullakko, K. and Lindroos, V.K., 'Internal friction and some other properties of shape memory Fe-Mn-Si based alloys', J. Phys. IV 112 (2003) 397400.

[27] Yoneyama, N., Setoda, T., Kumai, S., Sato, A., Komatsu, M. and Kiritani, M., 'Structural refinement and strengthening of an Fe-Mn-Si-Cr-Ni shape memory alloy by high-speed rolling', Mater. Sci. Eng., A 350 (1-2) (2003) 125-132.

[28] Kajiwara, S., Baruj, A., Kikuchi, T. and Shinya, N., 'Low-cost high-quality Fe-based shape memory alloys suitable for pipe joints', in Proceedings of SPIE, Vol. 5053 (SPIE, San Diego, 2003) 250-261.

[29] Wei, Z.G., Sandstrom, R., and Miyazaki, S., 'Shape-memory materials and hybrid composites for smart systems - Part I Shape-memory materials', J. Mater. Sci. 33 (15) (1998) 3743-3762.

[30] Brite Euram MANSIDE Project, 'Memory Alloys for New Seismic Isolation and Energy Dissipation Devices - Final Project Workshop', Rome, Italy, 1999.

[31] Brite Euram MANSIDE Project, Internet site of the Italian Seismic State Agency - www.serviziosismico.it/ PROG/1999 /manside.

[32] ISTECH, 'Shape Memory Alloy Devices for Seismic Protection of Cultural Heritage Structures', Proceedings of the Final Workshop, Ispra, Italy, 2000.

[33] Cardone, D., Dolce, M., Ponzo, F.C. and Coelho, E., 'Experimental behaviour of $\mathrm{R} / \mathrm{C}$ frames retrofitted with dissipating and re-centring braces', Journal of Earthquake Engineering 8 (3) (2004) 361-396.

[34] Ocel, J., DesRoches, R., Leon, R.T., Hess, W.G., Krumme, R., Hayes, J.R. and Sweeney, S., 'Steel beam-column connections using shape memory alloys', J. Struct. Eng., ASCE 130 (5) (2004) 732-740.

[35] Graesser, E.J. and Cozzarelli, F.A., 'Shape memory alloys as new materials for seismic isolation', J. Eng.Mech., ASCE 117 (11) (1991) 2590-2608

[36] Wittig, P.R. and Cozzarelli, F.A., 'Shape Memory Structural Dampers: Material Properties, Design and Seismic Testing', Technical Report NCEER-92-0013 (State University of New York at Buffalo, 1992).

[37] Thomson, P., Balas, G.J. and Nalbantoglu, V., 'Shape memory alloys for augmenting damping of flexible structures', AIAA96-3760, Proceedings of AIAA Guidance Navigation and Control Conference, San Diego, CA, 1996.

[38] Salichs, J., Hou, Z. and Noori, M., 'Vibration suppression of structures using passive shape memory alloy energy dissipation devices', J. Intell. Mat. Syst. Struct. 12 (2001) 671680.

[39] Dolce, M. and Cardone, D., 'Mechanical behavior of shape memory alloys for seismic applications, 2. Austenite NiTi wires subjected to tension', Int. J. Mech. Sci. 43 (11) (2001) $2657-2677$

[40] Krumme, R. and Hodgson, D.E., 'Hysteretic damping apparati and methods - US Patent Nr. 5-842-312', (1998)
[41] Castellano, M.G., 'Seismic protection of the basilica in San Francesco ad Assisi', (only available in italian), (2000), http: // rin365.arcoveggio.enea.it/GLIS/HTML/gn/assisi/g5assisi.htm.

[42] Indirli, M., 'Application of 'novel anti-seismic devices in the bell tower of the church in San Giorgio a Trignano', (2000), [only available in Italian], http://rin365.arcoveggio.enea.it /GLIS/HTML/gn/trignano/smatri.htm.

[43] DesRoches, R. and Delemont, M., 'Seismic retrofit of simply suported bridges using shape memory alloys', Engineering Structures 24 (3) (2002) 325-332.

[44] Wilde, K., Gardoni, P. and Fujino, Y., 'Base isolation system with shape memory alloy device for elevated highway bridges', Engineering Structures 22 (3) (2000) 222-229.

[45] Sun, S. and Rajapakse, R.K.N.D, 'Dynamic response of a frame with SMA bracing', in Proceedings of SPIE, Vol. 5053 (SPIE, San Diego, 2003) 262-270.

[46] Nae, F.A., Ikeda, T. and Matsuzaki, Y., 'The active tuning of a shape memory alloy pseudoelastic property', Smart Mater. Struct. 13 (3) (2004) 503-511.

[47] Shahin, A.R., Meckl, P.H. and Jones, J.D., 'Modeling of SMA tendons for active control of structures', J. Intell. Mater. Syst. Struct. 8 (1) (1997) 51-70.

[48] Williams, K., Chiu, G. and Bernhard, R., 'Adaptive-passive absorbers using shape-memory alloys', $J$. of Sound and Vibration 249 (5) (2002) 835-848.

[49] Liang, C. and Rogers, C.A., 'Design of shape memory alloy springs with applications in vibration control', J. Intell. Mater. Syst. Struct. 8 (1997) 314-322.

[50] Amato, I., 'The Sensual City', New Scientist (1994) 33-36.

[51] Maji, A.K. and Negret, I., 'Smart presstressing with shapememory alloy', J. Eng. Mech.,ASCE 124 (10) (1998) 11211128.

[52] Shen, Y.M., Du, Y.L., Sun, B.C. and Li, J.L., 'A study of SMA used for threaded connections having loosening-proof and anti-break functions', in 'Shape Memory Materials and Its Applications', (Trans Tech Publications, Zürich-Uetikon, 2001) 99-102.

[53] Soroushian, P., Ostowari, K., Nossoni, A. and Chowdhury, H., 'Repair and strengthening of concrete structures through application of corrective posttensioning forces with shape memory alloys', Transportation Reserarch Record (No. 1770) (2001) 20-26.

[54] Krstulovic-Opara, N. and Naaman, A.E.s 'Self-stressing fiber composites', ACI Structural Journal 97 (2) (2000) 335-344.

[55] Watanabe, Y., Miyazaki, E. and Okada, H., 'Enhanced mechanical properties of $\mathrm{Fe}-\mathrm{Mn}-\mathrm{Si}-\mathrm{Cr}$ shape memory fiber/plaster smart composite', Mater. Trans. 43 (5) (2002) 974-983.

[56] Miyazaki, E. and Watanabe, Y., 'Development of shape memory alloy fiber reinforced smart FGMs', in 'Functionally Graded Materials VII' (Trans Tech Publications, ZürichUetikon, 2003) 107-111.

[57] Deng, Z., Li, Q., Jiu, A. and Li, L., 'Behavior of concrete driven by uniaxially embedded shape memory alloy actuators", J. Eng. Mech., ASCE 129 (6) (2003) 697-703.

[58] Krstulovic-Opara, N., Nau, J., Wriggers, P. and KrstulovicOpara, L., 'Self-actuating SMA-HPFRC fuses for autoadaptive composite structures', Computer-Aided Civil and Infrastructure Engineering 18 (1) (2003) 78-94.

[59] Czaderski, C. and Motavalli, M., 'Shape memory alloys in civil engineering - Visions', SLA-Tec21 (19) (2003) 10-13 [only available in German]

[60] Czaderski, C., Hahnebach, B., and Motavalli, M., 'RC beam with variable stiffness and strength', Construction and Building Materials (accepted for publication in 2005). 
